\title{
EFFECTIVENESS OF TRANSFUSIONS OF FRESH AND LYOPHILIZED PLATELETS IN CONTROLLING BLEEDING DUE TO THROMBOCYTOPENIA *
}

\author{
BY DUDLEY P. JACKSON, $\dagger$ DALE K. SORENSEN, $\ddagger$ EUGENE P. CRONKITE, \\ VICTOR P. BOND § AND THEODORE M. FLIEDNER § \\ (From the Medical Research Center of The Brookhaven National Laboratory, Upton, N. Y. and \\ the Department of Medicine of The Johns Hopkins University and \\ Hospital, Baltimore, Md.)
}

(Submitted for publication April 15, 1959; accepted June 19, 1959)

Transfusion of platelets into thrombocytopenic recipients results in the control of hemorrhage if the infused platelets are viable and circulate in the recipient's blood in sufficient numbers $(1,2)$. Storage by commonly employed methods for brief periods alters platelets so that they will not circulate when infused (3). Infusions of platelets preserved by freezing (4) and lyophilization (5) have not resulted in increase of recipient's platelet levels although such infusions have been reported to control bleeding due to thrombocytopenia. The effectiveness was assayed by observing the degree of clinical bleeding in thrombocytopenic recipients before and after the infusion of preserved platelets $(4,5)$. However, such observations are difficult to quantify because bleeding in thrombocytopenic individuals is variable and intermittent. Some individuals with severe thrombocytopenia have no abnormal bleeding. Others with the same degree of thrombocytopenia may have serious and even fatal hemorrhage.

Thrombocytopenia is the major cause of bleeding in animals exposed to whole body irradiation (6). A characteristic of the hemorrhagic state following such irradiation is the appearance of large numbers of red blood cells in the lymph (7). Transfusions of viable platelets that circu-

\footnotetext{
* Supported by the United States Atomic Energy Commission and performed at the Medical Research Center of The Brookhaven National Laboratory. An abstract of this work was published in J. clin. Invest. 1958, 37, 904.

$\dagger$ John and Mary R. Markle Scholar in Medical Science, The Johns Hopkins University, School of Medicine; and Research Collaborator, Medical Department, Brookhaven National Laboratory.

$\ddagger$ University of Minnesota, College of Veterinary Medicine, St. Paul, Minn.

§ Medical Research Center, Brookhaven National Laboratory, Upton, N. Y.
}

lated in recipients suppressed the number of red blood cells in thoracic duct lymph of irradiated dogs (8). In the present studies, the effectiveness of lyophilized platelets was compared with the effectiveness of fresh platelets in suppressing the number of red blood cells in the thoracic duct lymph of irradiated dogs.

\section{MATERIALS AND METHODS}

Experimental animals. Adult mongrel dogs were housed in individual metabolism cages and fed Purina Dog Chow with a daily supplement of meat. Four dogs (430, 431, 440 and 441) received chlortetracycline daily per os beginning seven days after irradiation. Three dogs $(426,428$ and 435$)$ were given penicillin and dihydro-streptomycin, and one (442) was given chlortetracycline on the day of operation (cannulation of thoracic duct).

Technique of irradiation. Five dogs $(426,428,430,431$ and 441 ) received $500 \mathrm{r}$. whole body irradiation, and three $(435,440$ and 442$)$ received 550 r. All of the dogs were anesthetized with pentobarbital sodium during irradiation. Radiation was delivered by a General Electric Maxitron $\mathrm{X}$-ray machine operating at $250 \mathrm{KVP}, 30 \mathrm{ma}$. and filtered with $0.5 \mathrm{~mm}$. of copper and $1.0 \mathrm{~mm}$. of aluminum. The target-skin distance was $110 \mathrm{~cm}$. The dose rate at the skin surface was $27 \mathrm{r}$. per minute. Half of the total dose was delivered to each side of the body.

Cannulation of thoracic duct. The thoracic duct was cannulated between the tenth and seventeenth day following irradiation after the dogs became thrombocytopenic. One hour before surgery the animals were given approximately $100 \mathrm{ml}$. of corn oil per os to facilitate identification of the lymph channels. Pentobarbital sodium was administered intravenously for anesthesia, and 5 per cent glucose in 0.85 per cent sodium chloride solution was infused during the operation. The operative procedure of Ross, Furth and Bigelow (7) was employed, in which plastic (polyethylene) cannulae are introduced into the thoracic duct and into a branch of the jugular vein. The free ends of both of these cannulae were exteriorized. When the lymph was not being sampled, the free ends of the two cannulae were connected and the lymph allowed to flow into the venous system. 
Collection of and observations on lymph. Lymph was collected from the free end of the cannula in the thoracic duct, and the total output of lymph (ml. per minute) was measured. When the periods of sampling were prolonged, the dogs were maintained under pentobarbital sodium anesthesia and were given an intravenous infusion of 5 per cent glucose in 0.85 per cent sodium chloride solution. The rate of infusion was adjusted to approximate the rate of output of lymph.

Red blood cells in lymph samples were counted with an electronic counter. ${ }^{1}$ All samples were diluted with 0.85 per cent sodium chloride solution so that the cell concentration in the $0.5 \mathrm{ml}$. metered fell between 10,000 and 90,000 . The reproducibility of results with this counter is within approximately \pm 2 per cent of the mean $(9,10)$.

Results are expressed as the total output of red blood cells in the lymph per unit of time. These values were calculated as follows:

$\frac{\mathrm{ml} \text {. of lymph }}{\text { min. of collection }} \times \frac{\text { number of } \mathrm{RBC}}{\mathrm{ml} \text {. of lymph }}=\frac{\text { number of } \mathrm{RBC}}{\mathrm{min} \text {. of collection }}$.

Hematologic studies. Hematocrit values were determined by a microtechnique (11). Leukocytes were counted in blood diluted with 2 per cent acetic acid. A dilution of $1: 20$ was used until the total count fell below 1,000 per cu. mm., and then a dilution of $1: 10$ was used. Platelets were counted by the phase contrast technique of Brecher and Cronkite (12). Studies of blood coagulation were performed using previously described techniques (13).

Preparation of fresh platelet suspensions. Healthy donor dogs were anesthetized with thiopental sodium and blood was obtained from femoral artery punctures. The method (14) for the separation and concentration of the platelets was based on differential centrifugation and included the use of nonwettable equipment with disodium ethylenediaminetetraacetatic acid (EDTA) as the anticoagulant. The final suspension of platelets was usually completed within four to five hours of drawing the blood. The platelet suspensions were infused through plastic recipient sets with nylon filters.

Preparation of lyophilized platelets. Donor dogs were bled as for the preparation of fresh platelet suspensions. The technique of Klein and associates (5) was used for separation, concentration and lyophilization of the platelets. The only modifications were: $(a)$ silicone coated glassware was used in place of plastic blood bank equipment, (b) Triton was not used, and $(c)$ the final suspension of platelets before lyophilization was in 0.85 per cent sodium chloride solution containing 1 per cent EDTA.

The final platelet concentration before lyophilization was adjusted to $10,000,000$ platelets per cu. mm. The lyophilized platelets were stored at $-20^{\circ} \mathrm{C}$. for 5 to 21 days. The lyophilized material was reconstituted 30 minutes before use by addition of sterile, distilled water in an amount equal to the volume of the final platelet

1 Coulter Counter, Model A ; Coulter Electronics, 5227 N. Kenmore, Chicago, Ill. suspension before lyophilization. The reconstituted material was infused through plastic recipient sets with nylon filters. On the assumption that the recipient's blood volume was 7 per cent of body weight, infusion of 1.40 $\mathrm{ml}$. of this material per $\mathrm{Kg}$. body weight would be expected to raise the recipient's platelet level by approximately 200,000 per $\mathrm{cu}$. $\mathrm{mm}$. if the infused platelets circulated.

\section{RESULTS}

\section{Hematologic studies}

The changes in the leukocyte, hematocrit and platelet levels in the eight dogs were similar to those described previously by many investigators after amounts of whole body irradiation comparable to the amounts employed in these experiments. The mean control leukocyte count was 16,700 per cu. mm. By the sixth to eighth postirradiation day the leukocyte level was $<1,000$ per cu. $\mathrm{mm}$. in each of the irradiated animals. The mean control platelet count was 339,000 per $\mathrm{cu} . \mathrm{mm}$. and the mean control hematocrit value was 44.6 per cent. By the eleventh postirradiation day, the platelet level was $<10,000$ per cu. $\mathrm{mm}$. in each of the dogs and the mean hematocrit value was 32.5 per cent.

\section{Effects of infusion of lyophilized platelets alone}

Three dogs (430, 440 and 441) were given one or more infusions of lyophilized platelets but no fresh platelets.

Dog 430 was given 500 r. whole body irradiation. Cannulation of the thoracic duct was carried out 14 days later. The peripheral blood platelet count on the day of operation was $<5,000$ per cu. $\mathrm{mm}$. The initial lymph samples were bloody and observations on the lymph were begun upon com-

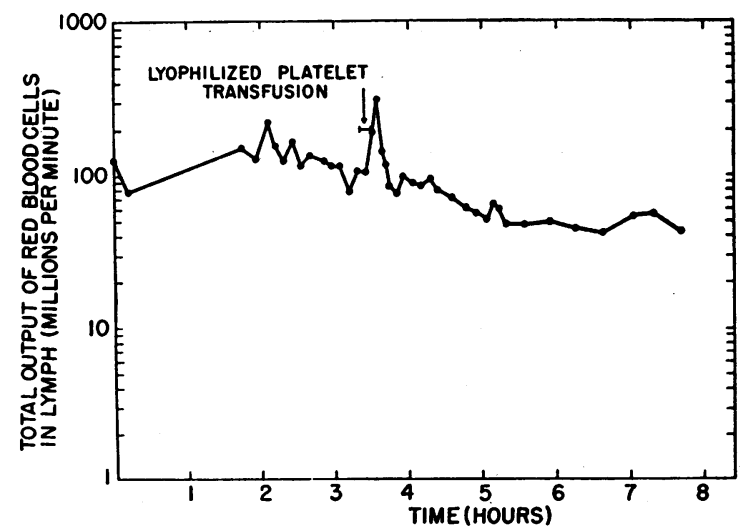

Fig. 1. 500 r. Whole Body Irradiation (Dog 430) 
pletion of the operation. Results are shown in Figure 1. The output of red blood cells in the lymph appeared stable over a three and a half hour control period. Eighteen $\mathrm{ml}$. (1.73 ml. per $\mathrm{Kg}$.) of lyophilized platelets then was infused over a nine minute interval. No increase in the recipient's circulating platelet level occurred following this infusion. The respiratory rate increased during the infusion. Coincident with the increased respiratory rate, the flow rate of the lymph increased from 0.67 to $1.57 \mathrm{ml}$. per min. The flow rate returned to control levels within 30 minutes of completion of the infusion. The total output of red blood cells in the lymph increased transiently coincident with the increase in flow rate. Thereafter the output of red blood cells stabilized at a level slightly below that of the control period and no further decrease in output occurred over the next four hours.

Dog 440 received $550 \mathrm{r}$. whole body irradiation. The thoracic duct was cannulated 11 days later and observations were begun immediately. Results are shown in Figure 2. The output of red blood cells in the lymph appeared stable over a control period of four hours. Seventeen $\mathrm{ml}$. $(1.44 \mathrm{ml}$. per $\mathrm{Kg}$.) of lyophilized platelets then was infused over a six minute interval. The platelet level of this recipient dog would have been expected to increase to approximately 200,000 per cu. mm. if all of these lyophilized platelets had circulated. However, the circulating platelet level did not increase. The dog vomited once immediately following the infusion and the respiratory rate increased transiently. The flow rate of the lymph increased from 0.47 to $1.22 \mathrm{ml}$. per minute and then returned to control levels in approxi-

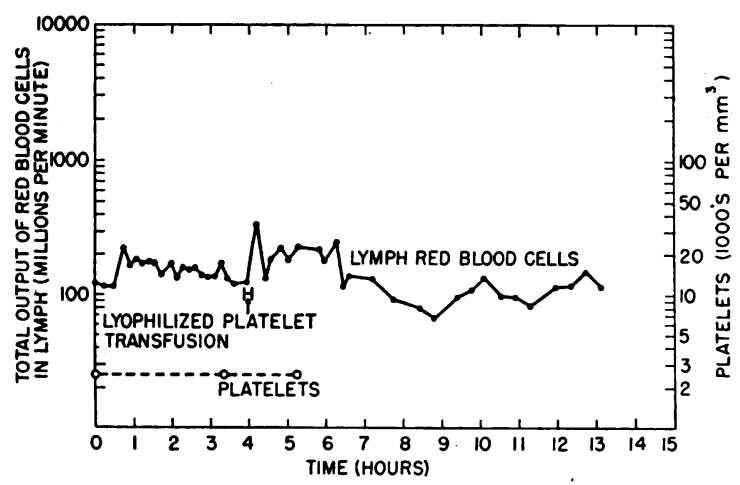

Fig. 2. 550 r. Whole Body Irradiation (Dog 440)

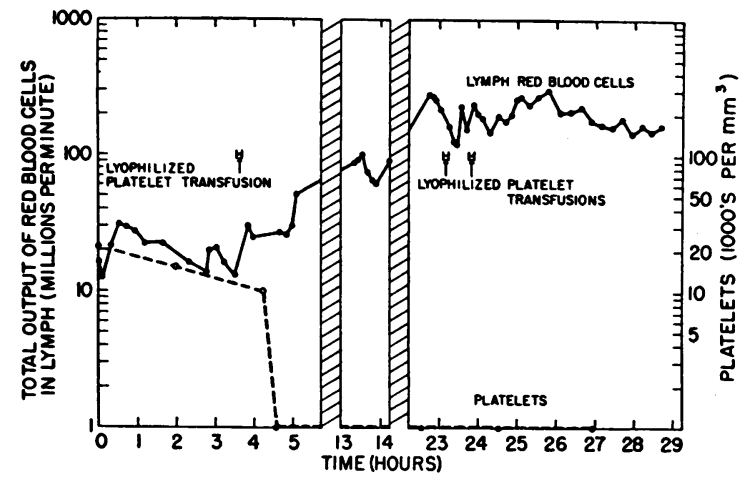

Fig. 3. 500 r. Whole Body Irradiation (Dog 441)

mately two hours. The total output of red blood cells in the lymph increased transiently, coincident with the increase in flow rate. Thereafter the output of red blood cells stabilized at a level approximately the same as that of the control period. There was no further fall in the output over the next seven hours.

Dog 441 was given 500 r. whole body irradiation. Nineteen days later the peripheral blood platelet count was $<5,000$ per cu. mm. The thoracic duct was cannulated on the twentieth postirradiation day. Because of anemia and shock, the animal was given a transfusion of $250 \mathrm{ml}$. whole blood as the operation was being completed. This transfused blood had been collected and stored at $4^{\circ} \mathrm{C}$. for seven days in a silicone coated bottle containing acid-citrate-dextrose solution. Platelet count on this blood just prior to the transfusion was 100,000 to 200,000 per cu. mm. but an accurate count was not possible because the platelets in the counting chamber were in large clumps. Fifteen minutes after this transfusion, the peripheral blood platelet count was 20,000 per cu. mm. Observations on the lymph were begun as soon as the operation was completed and the results are presented in Figure 3. The output of red blood cells in the lymph was lower than in the two previous experiments but appeared stable over a three and a half hour control period. Nineteen $\mathrm{ml}$. (1.44 $\mathrm{ml}$. per $\mathrm{Kg}$.) of lyophilized platelets then was infused over a five minute interval. There was no increase in the circulating platelet level following this infusion, and the output of red blood cells in the lymph did not decrease. The output of red blood cells in the lymph had increased markedly 22.5 hours after operation, and the circulating 
platelet level had decreased. Fourteen ml. (1.06 $\mathrm{ml}$. per $\mathrm{Kg}$.) of lyophilized platelets then was infused over a five minute interval. An additional $25 \mathrm{ml}$. (1.89 ml. per Kg.) of lyophilized platelets was infused over a three minute period after another interval of 35 minutes. This recipient's platelet level would have been expected to increase to approximately 400,000 per cu. $\mathrm{mm}$. if all of these lyophilized platelets $(2.95 \mathrm{ml}$. per $\mathrm{Kg}$.) had circulated. However, there was no such increase. Futhermore, the output of red blood cells in the lymph did not decrease. The flow rate of the lymph also did not change appreciably.

\section{Effects of infusion of lyophilized platelets followed by infusion of fresh platelets}

Four dogs $(426,428,435$ and 442$)$ received infusions of lyophilized platelets after which fresh platelets were administered.

Dog 426 received $500 \mathrm{r}$. whole body irradiation. Ten days later a platelet count was 10,000 per cu. $\mathrm{mm}$. The thoracic duct was cannulated on the eleventh postirradiation day. At this time the lymph appeared milky and was shunted back into the venous cannula. On the twelfth postirradiation day the dog was still eating and appeared in reasonably good condition. The peripheral blood platelet level was $<5,000$ per cu. mm., and the total output of red blood cells in the lymph was only 29.3 million per minute. Thus the observations on the lymph were interrupted, and the lymph again was shunted into the venous circulation. On the thirteenth postirradiation day, the output of red blood cells in the lymph had increased somewhat. The peripheral blood revealed a platelet count of $<5,000$ per cu. mm., a whole blood clotting time of 60 minutes, a plasma fibrinogen of $363 \mathrm{mg}$. per cent and markedly impaired clot retraction. Twenty-five $\mathrm{ml}$. (1.25 ml. per $\mathrm{Kg}$.) of lyophilized platelets was infused over a ten minute interval. Forty-five minutes after this infusion, the peripheral platelet level remained $<5,000$ per cu. $\mathrm{mm}$., the plasma fibrinogen was unchanged and was determined to be $362 \mathrm{mg}$. per cent, and clot retraction remained markedly impaired, but the whole blood clotting time had returned to normal and was determined to be 19 minutes. Observations on the lymph, however, were unreliable, because the dog was not anes- thetized during this infusion. Although no overt reaction to the infusion was apparent except for a transient increase in respiratory rate, the dog became very restless and active on several occasions and the flow rate of the lymph changed frequently and markedly. Observations on the lymph again were interrupted and the lymph shunted into the venous circulation. The output of red blood cells in the lymph increased strikingly by the fourteenth postirradiation day. The dog was anesthetized and continuous observations on the lymph were begun. Results are shown in Figure 4. After a control period of one and three-quarter hours, 25 $\mathrm{ml}$. (1.25 ml. per Kg.) of lyophilized platelets was infused over a 13 minute interval. No increase in the level of circulating platelets followed this infusion. There was a transitory increase in total output of red blood cells coincident with a transitory increase in flow rate of the lymph. The output of red blood cells then stabilized at a level approximately the same as that during the control period. Four and one-half hours later, $37 \mathrm{ml}$. ( $1.85 \mathrm{ml}$. per Kg.) of freshly separated and concentrated platelets was infused over a four minute interval. This platelet suspension contained 10,000,000 platelets per cu. mm. The recipient's platelet level would have been expected to increase to a level of approximately 270,000 per $\mathrm{cu}$. $\mathrm{mm}$. if all of these platelets had continued to circulate. The level actually increased from $<5,000$ to 145 ,000 per $\mathrm{cu}$. $\mathrm{mm}$. following this infusion, and a prompt and striking decrease in the total output of red blood cells in the lymph occurred. There was no untoward reaction to this infusion. The lymph clotted in the cannula for the first time in this experiment one hour after the infusion. The can-

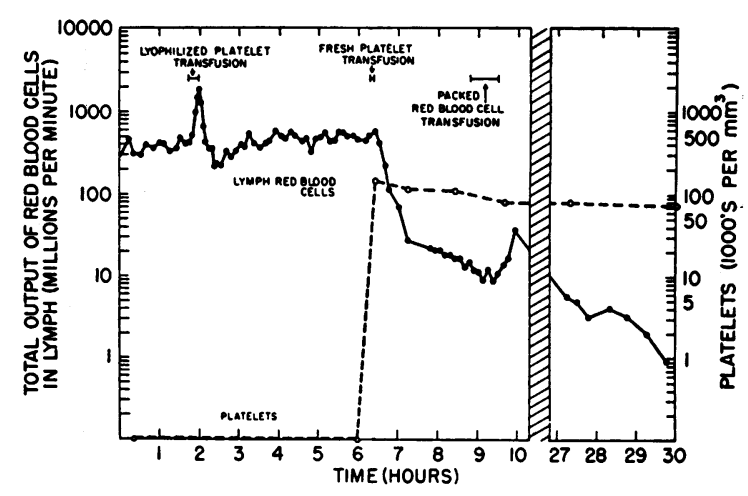

Fig. 4. 500 r. Whole Body IrRadiation (Dog 426) 
nula was flushed with physiological saline solution and the lymph flow re-established at its previous rate. The peripheral blood hematocrit was 23.5 per cent, and 2.5 hours after the infusion of fresh platelets, a transfusion of $400 \mathrm{ml}$. of packed red blood cells was given. These packed red blood cells had been obtained during the differential centrifugation procedures for the preparation of the fresh platelets. The peripheral blood hematocrit was raised to 31 per cent following this transfusion. The output of red blood cells in the lymph continued to fall over the next 21 hours and the circulating platelet level remained $>75,000$ per $\mathrm{cu}$. $\mathrm{mm}$.

$\operatorname{Dog} 428$ was given $500 \mathrm{r}$. whole body irradiation. Ten days later the thoracic duct was cannulated, and the lymph appeared white with a faint pink tint. The output of red blood cells in the lymph had increased by the eleventh postirradiation day. The peripheral blood at this time revealed a hematocrit of 17 per cent and a platelet count of $<5,000$ per cu. mm. The dog appeared moribund and observations on the lymph were begun. Results are shown in Figure 5 . After a control period of 30 minutes, $16.4 \mathrm{ml}$. (1.06 $\mathrm{ml}$. per $\mathrm{Kg}$.) of lyophilized platelets was infused over a 10 minute interval. The circulating platelet level did not increase after this infusion. The output of red blood cells in the lymph increased transiently, coincident with a transient increase in flow rate. Three hours later, $390 \mathrm{ml}$. of fresh platelet-rich plasma containing 250,000 platelets per cu. mm. was infused over a 40 minute interval. The recipient's platelet count was 32,000 per cu. $\mathrm{mm}$. immediately following this infusion. Five

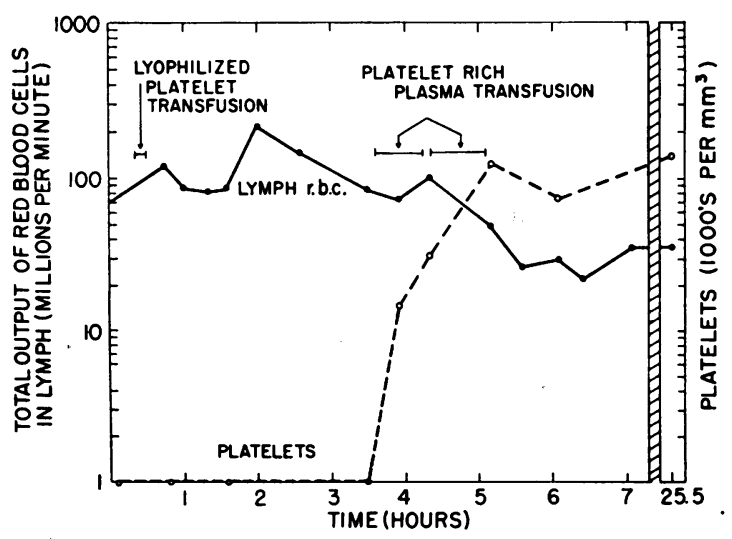

Fig. 5. 500 r. Whole Body IrRadiation (Dog 428)

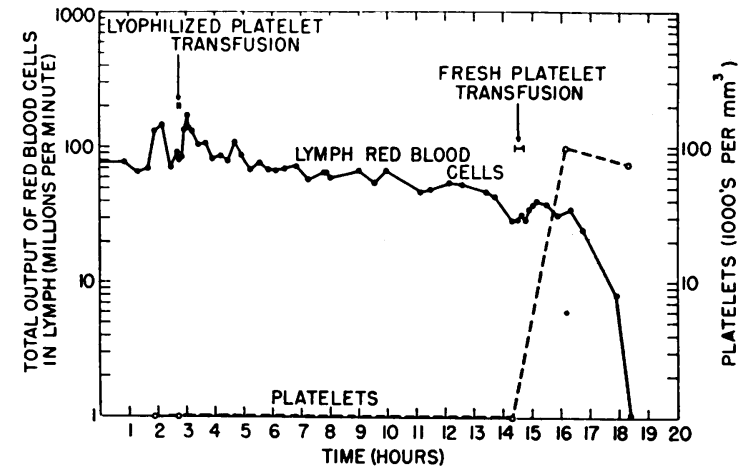

Fig. 6. 550 r. Whole Body Irradiation (Dog 435)

minutes later, $450 \mathrm{ml}$. of fresh platelet-rich plasma containing 330,000 platelets per cu. $\mathrm{mm}$. was infused over a 45 minute interval. The recipient's platelet level increased to 125,000 per cu. mm. following this infusion. The output of red blood cells gradually fell during the next two hours despite a transitory increase in flow rate of the lymph. The circulating platelet level was 140,000 per cu. $\mathrm{mm} .20$ hours after the last infusion and the output of red blood cells did not decrease further. Fresh platelet-rich plasma was used in this experiment in place of concentrated platelets because the dog probably would not have survived long enough for procedures of separation and concentration of the platelets.

Dog 435 received $550 \mathrm{r}$. whole body irradiation. Ten days later the peripheral blood platelet count was 35,000 per cu. $\mathrm{mm}$. and the thoracic duct was cannulated. The lymph was not grossly bloody at the completion of the operation and the total output of red blood cells in the lymph was $<10$,000,000 per minute. The lymph therefore was shunted into the venous circulation. The platelet count was $<5,000$ per cu. mm. on the eleventh postirradiation day and the output of red blood cells in the lymph was approximately $12,000,000$ per minute. The dog remained in fair general condition; observations again were interrupted and the lymph diverted into the venous circulation. The output of red blood cells had increased strikingly by the twelfth postirradiation day, and continuous observations on the lymph were begun. Results are shown in Figure 6. The output of red blood cells remained fairly stable over a two and threequarter hour control period. Twenty-six $\mathrm{ml}$. $(1.58 \mathrm{ml}$. per $\mathrm{Kg}$.) of lyophilized platelets then 
was infused over a five minute interval. There was no increase in the circulating platelet level following this infusion. The output of red blood cells in the lymph increased transiently coincident with a transitory increase in the flow rate of the lymph. The output of red blood cells remained fairly stable over the next 11 hours. Thirty-eight $\mathrm{ml} .(2.32 \mathrm{ml}$. per $\mathrm{Kg}$.) of freshly separated and concentrated platelets then was infused over an 18 minute interval. This suspension of platelets contained $10,000,000$ platelets per cu. $\mathrm{mm}$. The recipient's platelet level would have been expected to increase to approximately 330,000 per cu. $\mathrm{mm}$. if all of these platelets had circulated. Following the infusion, the recipient's platelet level actually increased from $<5,000$ to 100,000 per cu. mm., and there was a prompt and striking decrease in the total output of red blood cells in the lymph.

Dog 442 was given 550 r. whole body irradiation. The thoracic duct was cannulated 12 days later, and continuous observations of the lymph were begun. Results are shown in Figure 7. The total output of red blood cells in the lymph was very high and fairly stable during a one and onehalf hour control period. Twenty-one and onehalf $\mathrm{ml}$. (1.43 ml. per Kg.) of lyophilized platelets then was infused over a 14 minute interval. No increase in the level of circulating platelets followed. The output of red blood cells increased transiently, coincident with a transitory increase in flow rate of the lymph. Thereafter the output stabilized at a level approximating the control level. Ten and one-half $\mathrm{ml} .(0.70 \mathrm{ml}$. per $\mathrm{Kg}$. $)$ of freshly separated and concentrated platelets was infused over a 12 minute interval six and three-quarter hours later. This suspension contained $9,000,000$ platelets per cu. $\mathrm{mm}$. If all of

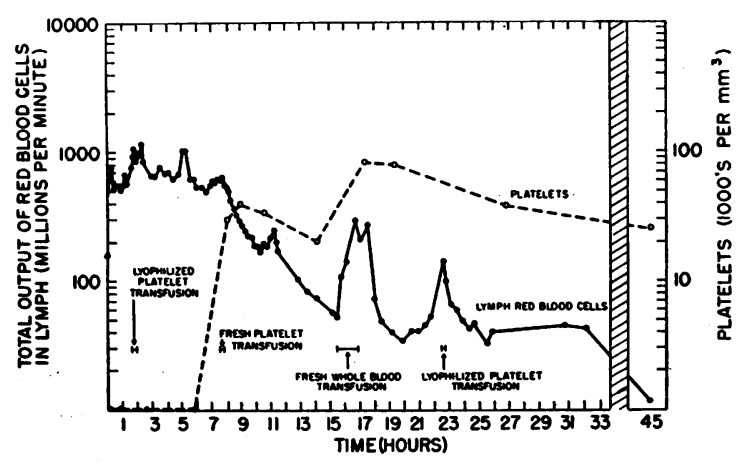

Fig. 7. 550 r. Whole Body Irradiation (Dog 442) these platelets circulated, the recipient's platelet level would have been expected to increase to a level of approximately 90,000 per cu. mm. Actually the recipient's platelets increased from $<5,000$ to 40,000 per cu. mm., and the output of red blood cells in the lymph decreased promptly and strikingly. The lymph flow rate did not change significantly and no untoward reaction to this infusion was observed. Seven hours later the peripheral blood hematocrit was 23 per cent. Then $500 \mathrm{ml}$. of fresh whole blood containing 230,000 platelets per cu. mm. was transfused over a 90 minute interval. This blood had been collected immediately prior to use in a nonsiliconed glass bottle containing acid-citrate-dextrose. The tubing of the donor and recipient sets was plastic. The recipient's platelet level increased from 20,000 to 85,000 per cu. $\mathrm{mm}$. following this transfusion. The recipient was flushed and shivered during the transfusion. At this time the flow rate of the lymph and the output of red blood cells in the lymph increased transiently. Thereafter the output of red blood cells continued to fall. Five hours later $20 \mathrm{ml}$. (1.33 ml. per Kg.) of lyophilized platelets was administered over a seven minute interval. There was no striking change in the circulating platelet level following this infusion. The output of red blood cells increased transiently coincident with a transitory increase in the flow rate of the lymph. Over the next seven hours, the output of red blood cells in the lymph remained fairly stable.

\section{Effects of infusion of fresh platelets followed by infusion of lyophilized platelets}

One dog (431) received a transfusion of fresh whole blood after which lyophilized platelets were administered.

$\operatorname{Dog} 431$ received $500 \mathrm{r}$. whole body irradiation. The thoracic duct was cannulated 13 days later, but the cannula became dislodged as the operative procedure was being completed. The thoracic duct was immediately cannulated again. The operative procedures required a total of five hours. The lymph was pink after completion of the second procedure and observations on the lymph were begun. Results are shown in Figure 8 . The dog appeared in a state of shock two hours after the operations. An infusion of $400 \mathrm{ml}$. of platelet- 


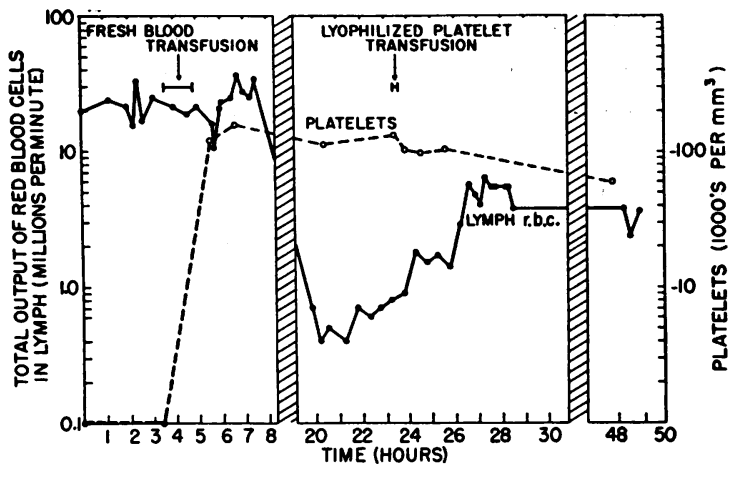

Fig. 8. 500 r. Whole Body Irradiation (Dog 431)

poor plasma was given over a 60 minute interval. This plasma had been obtained during the differential centrifugation for the preparation of lyophilized platelets and had been stored at $4^{\circ} \mathrm{C}$. for 25 days. The recipient's platelet count did not increase following this infusion and no striking change in the output of red blood cells in the lymph occurred. Two hours later a transfusion of 500 $\mathrm{ml}$. of fresh whole blood was administered over a one and one-quarter hour interval. This blood was collected immediately prior to use in an uncoated glass bottle containing acid-citrate-dextrose solution with the use of plastic tubing. The blood contained 400,000 platelets per cu. $\mathrm{mm}$. The recipient's platelet level increased from $<5,000$ to 160,000 per cu. mm. following this transfusion, and the output of red blood cells in the lymph fell strikingly. Thereafter, the output began to rise slowly. Twenty $\mathrm{ml}$. (1.42 ml. per Kg.) of lyophilized platelets was infused over a five minute interval 18 hours later. The recipient's platelet level decreased slightly following this infusion and the output of red blood cells continued to increase. The circulating platelet level was 60,000 per cu. $\mathrm{mm} .48$ hours after the operations and the output of red blood cells had increased somewhat, although not to levels so high as at the start of the experiment when the platelets were lower.

\section{DISCUSSION}

Infusions of lyophilized platelets did not increase platelet levels and had no hemostatic effect in irradiation hemorrhage under the conditions of these experiments. The number of lyophilized platelets infused into each recipient was approximately the number of platelets contained in a vol- ume of normal dog blood equal to the recipient's total blood volume. Infusions of fresh, viable platelets did increase recipient's platelet levels and striking hemostatic effects were noted.

Our results agree. with those of Woods, Gamble, Furth and Bigelow (8) who first used the output of red blood cells in thoracic duct lymph in irradiated dogs to measure the hemostatic effectiveness of various substances. Their experiments emphasized the hemostatic effectiveness of intact platelets that circulated in recipient animals. They also reported, without giving experimental details, that no hemostatic effect could be demonstrated in the test system following infusion of lyophilized platelets, frozen and thawed platelets or platelets disrupted by ultrasonic or supersonic vibrations, thromboplastin or rutin.

Fliedner and associates (15), using rats, reported that fresh, viable platelets that circulated in recipients completely controlled irradiation hemorrhage. In contrast, lyophilized platelets did not control the hemorrhage and did not circulate in recipients. Gross observations of bleeding, microscopic study of lymph node sections for evidence of bleeding, platelet counts, hematocrit values and susceptibility to bleeding from minor trauma were used to gauge the hemostatic effectiveness of the test substances in these studies.

Klein and associates have reported hemostatic benefit following infusions of platelets preserved by freezing (4) and by lyophilization (5) as judged by cessation of clinical bleeding in thrombocytopenic patients. The hemostatic effects were noted even though the recipient's circulating platelet levels did not increase following the infusions of the preserved platelets. Other platelet preparations and platelet substitutes that do not raise recipient platelet levels have been reported to have hemostatic effects in thrombocytopenic recipients $(16,17)$.

The question of whether a particular platelet preparation, fraction, or substitute that does not increase a recipient's platelet level, exerts a hemostatic effect on bleeding due to thrombocytopenia is difficult to answer. Measurements of capillary integrity (bleeding time and capillary resistance tests) and of blood coagulation (prothrombin consumption, thromboplastin generation, clot retraction, and so forth) can be made before and after administration of the test substance. Many of 
these tests are difficult to reproduce and quantify, and the degree of bleeding in thrombocytopenic individuals is not quantitatively related to results of most of these tests. Also, hemostasis is not assured even if all of these tests are brought to normal by the test substance.

One must, therefore, measure the degree or severity of bleeding in thrombocytopenic states before and after administration of a test substance in order to determine the hemostatic effectiveness of the substance. Such measurements can be made on thrombocytopenic patients or on experimental animals rendered thrombocytopenic. Studies of thrombocytopenic patients are difficult to control and to quantify because the type and severity of bleeding vary spontaneously. Adequate controls of the factors involved are more readily achieved by the use of experimental animals rendered thrombocytopenic. The comparative effectiveness of various agents (fresh and lyophilized platelets) in controlling gross and microscopic bleeding in rats rendered thrombocytopenic by whole body irradiation has been reported. The degree of bleeding in treated animals was compared with the degree of bleeding in paired controls (15). The present report describes the comparative effectiveness of fresh and lyophilized platelets in reducing the output of red blood cells in the thoracic duct lymph of irradiated, thrombocytopenic dogs.

The method described in the present report had certain advantages, including: (a) thrombocytopenia was regularly and predictably produced by the dose range of whole body irradiation employed; $(b)$ bleeding, including an increase in output of red blood cells in the lymph, was observed in every untreated animal that survived for a sufficient period; $(c)$ enumeration of red blood cells in the lymph served as a semiquantitative measure of the degree of bleeding; $(d)$ agents (viable platelets) known to be effective in controlling irradiation hemorrhage were always effective; and (e) an animal served as its own control. Some of the disadvantages of this test system were: $(a)$ the operative procedure required adequate surgical skill; $(b)$ the thoracic duct cannula had to be placed within the duct itself and not in an isolated segment of the external jugular vein (this precaution was necessary in order to preclude leakage of blood from small tributary veins into the segment of external jugular vein with resultant admixing of blood and lymph); (c) an effective agent had to be given after administration of an ineffective agent to be certain that the lymph could be cleared (see $b$ above); $(d)$ after administration of an effective agent the lymph occasionally clotted and suitable care was necessary to assure adequate flow; and $(e)$ the flow rate of the thoracic duct lymph was not constant, and the total output of red blood cells in the lymph had to be measured. During the performance of these experiments, changes in respiratory rate, physical activity, rate of intravenous hydration (in anesthetized animals), vomiting and defecation influenced the flow rate of the lymph.

\section{SUMMARY}

Eight dogs were rendered thrombocytopenic by the administration of 500 to $550 \mathrm{r}$. whole body irradiation. After thrombocytopenia developed, the thoracic duct of each dog was cannulated, and large numbers of red blood cells were observed in the thoracic duct lymph. The hemostatic effectiveness of fresh and lyophilized platelets in reducing the output of red blood cells in the lymph was compared.

Lyophilized dog platelets were infused into each dog in amounts calculated to increase the recipient's platelet level by approximately 200,000 per cu. $\mathrm{mm}$. The circulating platelet levels of the recipients did not increase following infusions of lyophilized platelets, and the output of red blood cells in the lymph did not decrease significantly.

Five of the dogs also received infusions of freshly separated, viable platelets. Fresh platelets were administered after the administration of lyophilized platelets in four of the animals, and in one the fresh platelets were administered initially. The circulating platelet levels of the recipients increased following infusions of fresh platelets, and the output of red blood cells in the lymph decreased strikingly.

\section{REFERENCES}

1. Tocantins, L. M., Harrington, W. J., Smith, C. H., Cronkite, E. P., Conley, C. L., and Gardner, F. H. Discussion on transfusion of platelets and platelet substitutes. Blood 1958, 13, 1089.

2. Cronkite, E. P., and Jackson, D. P. The use of platelet transfusions in hemorrhagic disease in Progress in Hematology, L. M. Tocantins, Ed. 
New York, Grune and Stratton, 1959, vol. 2, p. 239.

3. Jackson, D. P., Krevans, J. R., and Conley, C. L. Mechanism of the thrombocytopenia that follows multiple whole blood transfusions. Trans. Ass. Amer. Phycns 1956, 69, 155.

4. Klein, E., Toch, R., Farber, S., Freeman, G., and Fiorentino, R. Hemostasis in thrombocytopenic bleeding following infusion of stored, frozen platelets. Blood 1956, 11, 693.

5. Klein, E., Farber, S., Djerassi, I., Toch, R., Freeman, G., and Arnold, P. The preparation and clinical administration of lyophilized platelet material to children with acute leukemia and aplastic anemia. J. Pediat. 1956, 49, 517.

6. Cronkite, E. P., and Brecher, G. The experimental therapy of the hemorrhagic phase of the radiation syndrome with platelet transfusions. Acta Radiol. 1954, Suppl. 116, 376.

7. Ross, M. H., Furth, J., and Bigelow, R. R. Changes in cellular composition of the lymph caused by ionizing radiations. Blood 1952, 7, 417.

8. Woods, M. C., Gamble, F. N., Furth, J., and Bigelow, R. R. Control of the post-irradiation hemorrhagic state by platelet transfusions. Blood 1953, 8, 545.

9. Brecher, G., Schneiderman, M., and Williams, G. Z. Evaluation of electronic red blood cell counter. Amer. J. clin. Path. 1956, 26, 1439.

10. Mattern, C. F. T., Brackett, F. S., and Olson, B. J. Determination of number and size of particles by electrical gating: Blood cells. J. appl. Physiol. 1957, 10, 56.

11. Guest, G. M., and Siler, V. E. A centrifuge method for the determination of the volume of cells in blood. J. Lab. clin. Med. 1934, 19, 757.

12. Brecher, G., and Cronkite, E. P. Morphology and enumeration of human blood platelets. J. appl. Physiol. 1950, 3, 365.

13. Jackson, D. P., Hartmann, R. C., and Busby, T. Fibrinogenopenia complicating pregnancy. Clinical and laboratory studies. Obstet. and Gynec. 1955, 5, 223.

14. Dillard, G. H. L., Brecher, G., and Cronkite, E. P. Separation, concentration, and transfusion of platelets. Proc. Soc. exp. Biol. (N. Y.) 1951, 78, 796.

15. Fliedner, T. M., Sorensen, D. K., Bond, V. P., Cronkite, E. P., Jackson, D. P., and Adamik, E. Comparative effectiveness of fresh and lyophilized platelets in controlling irradiation hemorrhage in the rat. Proc. Soc. exp. Biol. (N. Y.) 1958, 99, 731.

16. Stefanini, M., and Kistner, S. A. Platelets, platelet factors and platelet substitutes in the management of thrombocytopenic states (abstract). (Proc. 6th Congr. Int. Soc. Blood Transfusion, 1956) Acta Haematol. 1958, Suppl. 7, 378.

17. Stefanini, M., and Kistner, S. Use of platelet derivatives and platelet substitutes in the management of thrombocytopenic states (abstract). Clin. Res. 1957, 5, 151. 